\title{
Neuropsychological Signs of Alzheimer's Disease 8 Years Prior to Diagnosis
}

\author{
Nicole S. Schmid ${ }^{\mathrm{a}}$, Kirsten I. Taylor ${ }^{\mathrm{a}, \mathrm{b}}$, Nancy S. Foldic ${ }^{\mathrm{c}}$ Manfred Berres ${ }^{\mathrm{d}}$ and Andreas U. Monsch ${ }^{\mathrm{a}, *}$ \\ ${ }^{a}$ Memory Clinic, Department of Geriatrics, University Hospital, Basel, Switzerland \\ ${ }^{\mathrm{b}}$ Centre for Speech, Language and The Brain, Department of Experimental Psychology, University of Cambridge, \\ Cambridge, $U K$ \\ ${ }^{\mathrm{c}}$ Department of Psychology, Queens College and The Graduate Center, City University of New York, NY, USA \\ ${ }^{\mathrm{d}}$ Department of Mathematics \& Technology, RheinAhrCampus, Remagen, Germany
}

Handling Associate Editor: Mark Bondi

Accepted 21 November 2012

\begin{abstract}
We investigated the earliest neuropsychological changes in Alzheimer's disease (AD) by comparing the baseline performance of 29 individuals who subsequently developed AD within an average of $7.91 \pm 2.70$ years with 29 pairwisematched individuals who remained cognitively healthy $(\mathrm{NC})$. We hypothesized that subtle, qualitative changes in cognition precede clinical $\mathrm{AD}$ by several years, and therefore examined subjective as well as standard quantitative measures of cognition, in addition to subjective estimates of mood and medical status. Participants were selected from the 825 members of the longitudinal BASEL study (BAsel Study on the ELderly), all of whom had been ApoE-genotyped and received comprehensive bi-annual neuropsychological assessments. Within 13 years, 29 were diagnosed with probable AD. Each individual who progressed to $\mathrm{AD}$ (AD-P) was pairwise matched to a NC participant based on age, education, demographic status, observation period, and, importantly, ApoE genotype. A regression analysis using the lasso technique identified which of 115 neuropsychological variables best discriminated baseline NC from baseline AD-P performance. This analysis yielded eleven neuropsychological variables that optimally discriminated the two groups (correct classification rate: 60.4\%): 1) Intrusions and 2) response bias in verbal learning and memory tasks; 3) delayed figure recall; 4-6) three Wechsler Adult Intelligence Scale (WAIS) Block Design subtest variables; 7-8) number of errors and repetitions on letter fluency; and 9-11) self-report of memory problems, a feeling of sadness, and cardiac problems. These results suggest that the preclinical neuropsychological cascade to AD includes subtle but identifiable qualitative impairments in verbal and visual memory, visuospatial processing, error control, and subjective neuropsychological complaints.
\end{abstract}

Keywords: Aging, Alzheimer disease, depressive symptoms, mild cognitive impairment, neuropsychological tests

Supplementary data available online: http://dx.doi.org/10.3233/JAD-121234

\section{INTRODUCTION}

The identification of patients in the earliest possible stages of Alzheimer's disease (AD) is a prerequisite for the development and implementation of preventive

\footnotetext{
*Correspondence to: Dr. Andreas U. Monsch, Memory Clinic, Department of Geriatrics, University Hospital, Schanzenstrasse 55, 4031 Basel, Switzerland. Tel.: +41 26531 93; Fax: +41 26537 94; E-mail: andreas.monsch@unibas.ch.
}

and therapeutic treatments. This study focuses on the earliest changes in neuropsychological functioning in $\mathrm{AD}$ [1]. Importantly, we investigated not only standard, quantitative performance measures, but also subjective and qualitative measures of neuropsychological functioning [2,3] and mood [4], which potentially accompany quantitative changes in episodic memory commonly considered to mark the beginning stages of $\mathrm{AD}[5]$. 
A number of large-scale longitudinal studies provide valuable information about the neuropsychological characteristics of very early stage AD. We summarized those studies which had (1) long observation periods, (2) at least three testing visits, and (3) which administered comprehensive neuropsychological test batteries (see Supplementary Table 1; available online: http://www.j-alz.com/issues/34/vol342.html\#supplementarydata10). As expected, all studies that assessed verbal episodic memory reported that it was the first or among the first cognitive functions to be affected in future AD patients. When assessed, some studies found that nonverbal episodic memory also declined first and in tandem with verbal episodic memory [6-9]. Some studies reported that frontal lobe functions (e.g., executive functioning as measured by the Trail Making Test B, and abstract reasoning abilities) deteriorated at the same assessment as episodic memory functions [6, 10-14], or at the visit following the documentation of episodic memory impairments $[15,16]$. Several studies reported that semantic fluency, a common measure of semantic memory, was either among the first functions affected [6, 7, 9, 10, 12], or that it deteriorated several years following episodic memory dysfunction [8, 16, 17]. However, Amieva and colleagues [15] found that semantic fluency was the first cognitive function affected, two years prior to abstract reasoning impairments and three years prior to nonverbal episodic memory impairments. These findings were largely confirmed in a comprehensive meta-analysis by Bäckman et al. [18]. These authors found that the preclinical phase of the disease is characterized by impairments in episodic memory, executive functioning, and perceptual speed, while standard measures of verbal ability, visuospatial skills, and attention were only moderately impaired.

Several recent analyses from longitudinal studies on the earliest detectable changes in cognitive functioning in the preclinical phase of $\mathrm{AD}$ focused on 'change' or 'inflection' points in cognitive functioning, i.e., points in time when cognitive functioning in future $\mathrm{AD}$ patients declines faster than cognitive functioning of those who remain cognitively healthy [16, 19-21]. Analyses from both the Bronx Aging Study [19] and the Baltimore Longitudinal Study of Aging (BLSA) [16] found that episodic memory declined at similar rates, with change points 8 years and up to 15 years prior to diagnosis, respectively. However, Riley and colleagues [20] found faster rates of cognitive decline in semantic memory and visuospatial construction in future $\mathrm{AD}$ patients' compared to individuals who remained cognitively healthy. Other studies have likewise reported change points in visuospatial functioning [21, 22] and semantic memory functioning [22]. Taken together, longitudinal studies of cognitive functioning in future AD patients suggest that bilateral medial and anterior temporal lobe as well as frontal lobe dysfunction underpin the earliest cognitive impairments in $\mathrm{AD}$, consistent with the sites of beginning neurofibrillary pathology [23], and that these changes appear approximately seven years prior to diagnosis.

Early pathological changes in $\mathrm{AD}$ may be manifested in subtle, qualitative neuropsychological dysfunction, before quantitative impairments emerge [2]. While most longitudinal studies have not addressed this hypothesis, the neuropsychological literature has documented qualitative abnormalities in AD patients' neuropsychological performance that represent potential candidates for qualitative preclinical markers. For example, intrusion errors in verbal episodic memory tests were significantly more frequent in $\mathrm{AD}$ patients than in normal controls [24], and were associated with low levels of choline acetyltransferase and large numbers of cortical senile plaques in an autopsy study [3]. AD patients' verbal episodic memory performance is also characterized by poor recognition discriminability with an abnormally liberal response bias [25]. Finally, $\mathrm{AD}$ patients demonstrate a reduced error control as measured by an increased number of errors and repetitions on tasks such as verbal fluency [2]. Thus, the search for preclinical neuropsychological markers may benefit from including not only participants' quantitative scores, but also qualitative performance measures that elaborate on how participants performed the task.

Other research suggests that changes in mood, especially depressive symptoms, may surface years before the diagnosis of dementia [26]. For example, more depressive symptoms were observed in patients in the preclinical stage of $\mathrm{AD}$ than in nondemented persons in the Kungsholmen Project [27]. In the Religious Orders Study, Wilson and colleagues [28] found that the number of depressive symptoms at baseline predicted future $\mathrm{AD}$, and that risk for the disease increased by about $20 \%$ with each additional symptom of depression. The PAQUID (Personnes Agées QUID) study [29] also found that depressive symptomatology in men appeared prior to a diagnosis of dementia. However, Chen and colleagues [30] failed to confirm this temporal relationship in the Monongahela Valley Independent Elders Survey (MoVIES) study, and suggested that depressive symptoms co-occur with, rather than predate, cognitive symptoms associated with dementia. These findings suggest that the predictive utility 
Table 1

Tests and neuropsychological domains subjected to analyses with corresponding number of variables per test (No)

\begin{tabular}{|c|c|c|}
\hline Test Domains tested & & No \\
\hline Medical background & $\begin{array}{l}\text { Subjective memory complaints; history of: falls, diabetes, stroke, smoking, alcohol dependency; heart problems; } \\
\text { family history of cognitive impairment }\end{array}$ & 9 \\
\hline Mood & Questionnaire for the Diagnosis of Depression according to DSM-IV [56] & 19 \\
\hline General abilities & Mini-Mental State Examination [61]; & 2 \\
\hline Psychomotor speed & Trail Making Test-A [62] & 1 \\
\hline Attention & Computerized Test of Attention [63] & 8 \\
\hline Memory & $\begin{array}{l}\text { German version of the California Verbal Learning Test [64]; CERAD [36] word list; CERAD Figures, delayed } \\
\text { recall }\end{array}$ & 29 \\
\hline \multirow[t]{2}{*}{ Language } & $\begin{array}{l}\text { Boston Naming Test [65], } 15 \text { items; Boston Naming Test, } 45 \text { items [65]; Wechsler Adult Intelligence Scale } \\
\text { (WAIS)-R, Vocabulary [48] }\end{array}$ & 10 \\
\hline & Equivalent of the National Adult Reading Test [66], i.e. the Mehrfach-Wortwahl-Test [67] & 1 \\
\hline Constructional praxis & CERAD Figures copy; WAIS-R Block Design [48] & 9 \\
\hline Executive functioning & $\begin{array}{l}\text { Trail Making Test-B (TMT-B [62]); TMT-B/TMT-A ratio; Semantic and Phonemic fluency (animals/tools/food, } \\
\text { G-/O-/S-words) [68]; Clock Drawing Test [69] }\end{array}$ & 27 \\
\hline
\end{tabular}

of depressive symptomatology, together with measures of cognitive functioning in $\mathrm{AD}$, requires further investigation.

The predictive value of measures related to both cognition and mood, i.e., subjective cognitive complaints, may be associated with a higher risk to develop $\mathrm{AD}$ [31]. Reisberg and coworkers suggested that selfreported concerns may be a harbinger of further cognitive decline, i.e., that future $\mathrm{AD}$ patients may be aware of a decline in their cognitive functioning before it is manifested by poor neuropsychological test performance [32]. These measures may be especially important for very high-functioning individuals whose initial decline from a near ceiling performance level is often difficult to quantify with traditional normative datasets in which they are underrepresented. Indeed, based on the cognitive reserve hypothesis [33], high functioning individuals may have a different course of preclinical cognitive decline whereby the successful compensation of impairments is accompanied by an awareness that such compensation was necessary, i.e., a subjective awareness of cognitive difficulties without corresponding quantitative impairments on neuropsychological testing.

The purpose of the present study was to determine the earliest neuropsychological changes in AD in members of the BAsel Study on the Elderly (BASEL study). This cohort has been followed bi-annually for up to 13 years with a medical screening questionnaire and comprehensive neuropsychological assessment addressing all major cognitive domains, mood and subjective measures of neuropsychological functioning, and medical status. We compared the baseline performance of 29 individuals who progressed to AD (AD-P) over the course of 8 years with 29 carefully matched individuals who had remained cognitively healthy within the same timeframe (normal control (NC) group). Since the emergence of $\mathrm{AD}$ is known to be influenced by demographic and genetic factors [34], most notably age, education, gender, and the presence of an ApoE $\varepsilon 4$ allele, the $\mathrm{AD}-\mathrm{P}$ and $\mathrm{NC}$ groups were pairwise matched on these variables. We compared baseline performance of the AD-P and the NC individuals on standard quantitative cognitive performance measures, and, critically, on qualitative measures of cognition, and subjective measures of cognition, mood, and medical status.

\section{MATERIALS AND METHODS}

\section{Participants}

All participants were members of the Basel study which originated in 1959 with a cohort of circa 6,500 healthy individuals who were studied with respect to cardiovascular risk factors, similar to the Framingham study. In 1997 all available and willing participants were invited back to participate in a new study focusing on preclinical cognitive markers of AD (BAsel Study on the ELderly) [35]. Cognitive screening consisted of a medical history questionnaire, the Consortium to Establish a Registry for Alzheimer's Disease - Neuropsychological Assessment Battery (CERAD-NAB, [36]), where cognitively healthy individuals were defined as those with $\mathrm{z}$-scores $\leq-1.96$ on no more than one of the eleven CERAD-NAB variables, as well as ApoE-genotyping [37] and an interview with a significant other, when appropriate. All cognitively healthy individuals with at least one ApoE4 allele, and an age, education, and gender matched group of cognitively healthy, non-ApoE4 individuals (total $n=825$ ) were assessed bi-annually with a comprehensive neuropsychological battery (see Table 1), a medical interview, 
and informant history. If any self- or informant reported concerns about a cognitive change, a referral was made to the Memory Clinic of the Basel University Hospital for additional examinations that included magnetic resonance imaging (MRI), medical assessment, and full blood and serum analyses. Between 1997 and 2010, 53 individuals developed dementia, of whom $29(55 \%)$ were diagnosed with probable AD $[38,39]$. This prevalence corresponds to an annual incidence rate of 0.5 per 100 person-years. Mayeux and Stern [40] described higher annual incidence rates of 1.7-3.2 per 100 person-years for comparably aged individuals. The relatively low incidence rate in the present sample may be due to the stringent cognitive and neurologic inclusion criteria employed, which ensured the inclusion of optimally (as opposed to typically) aging individuals.

Each of the 29 AD-P individuals was matched to one $\mathrm{NC}$ individual. The $\mathrm{NC}$ group represents a highly robust normative sample [41], and all $\mathrm{NC}$ participants remain healthy to date. All cognitive measures were available as standardized z-scores which were corrected for age, gender, and education. Since demographically-adjusted z-scores were not available for all clinical variables, the AD-P and NC groups were additionally pairwise matched according to the following criteria: 1) the length of the observation period, 2) gender, 3) age ( \pm 4 years), 4) education ( \pm 4 years) and (5) presence of at least one ApoE $\varepsilon 4$ allele. As expected, the groups did not differ with respect to any of these variables or baseline Mini-Mental State Exam (MMSE) scores (Table 2). Moreover, the selected individuals $(n=58)$ did not differ from the original cohort $(n=825)$ with respect to MMSE score $(t(820)=0.500, p=0.31)$ or gender $\left(\chi^{2}(1, n=825)=0.306, p=0.6\right)$. However, participants in the present study differed marginally from the entire cohort with respect to education $(12.8$ y versus $12.1 \mathrm{y}$, respectively; $t(823)=-1.851, p=0.065)$ and were on average 4.48 years older $(t(823)=-6.609$, $p<0.0001)$. This study was approved by the local Ethics Committee of Both Basels. All participants gave written informed consent after receiving information on the study, according to the Declaration of Helsinki.

\section{Statistical analyses}

Baseline data from the two groups were submitted to statistical analyses (Table 1, Supplementary Table 2). As the total number of variables $(k=115)$ outnumbered the number of participants in each group $(n=29)$, the "lasso" (least absolute shrinkage and selection operator) technique [42] for regression analysis was
Table 2

Baseline characteristics and observation period (mean \pm SD) of normal control participants (NC) and individuals who progressed to AD (AD-P)

\begin{tabular}{lcc}
\hline & NC $n=29$ & AD-P $n=29$ \\
\hline Gender (men:women) & $11: 18$ & $11: 18$ \\
Age (years) & $73.5 \pm 4.60$ & $73.3 \pm 4.63$ \\
Education (years) & $12.9 \pm 3.33$ & $12.7 \pm 3.12$ \\
Mini-Mental Status Examination & $28.4 \pm 1.52$ & $28.9 \pm 1.10$ \\
\% ApoE $\varepsilon 4$ positive & $52 \%$ & $52 \%$ \\
Observation period (years) & $7.22 \pm 2.81$ & $7.91 \pm 2.70$ \\
\hline
\end{tabular}

used to identify those variables that best discriminated between the two groups. The lasso method yields estimates of the regression coefficients, but not their standard errors, and minimizes the sums of squares of the residuals under the constraint that the sum of the absolute coefficients, also known as L1 norm, is restricted to: $\mathrm{L} 1=\sum\left|\hat{\beta}_{j}\right| \leq t$. Bound $t$ regulates the amount of shrinkage and the coefficients of some variables are shrunk to zero. Let $t_{0}$ be the maximal sum of the absolute coefficients of the full model without shrinkage, and $s=t / t_{0}$ the amount of shrinkage. Smaller s's are associated with a greater shrinkage of coefficients and stricter variable selection. The optimal amount of shrinkage is determined by a 10 -fold cross-validation, i.e., the sample is randomly split into ten subsamples, and each subsample is predicted by a model estimated from the other nine subsamples, where the optimization criterion is the correct classification rate (CCR). The lasso method combines the advantages of subset selection (i.e., good interpretability by selecting covariates with a high impact on the dependent variable) and ridge regression (i.e., improving of the stability of the estimates).

Thus, the lasso technique is a procedure that penalizes large coefficients by constraining the sum of the absolute coefficients (L1) to equal to or less than an absolute term $t$. By reducing $t$, the L1-norm shrinks by the same amount. Consequently, dispensable coefficients shrink to zero and are removed from the model. This action leads to the desired selection of variables, but also raises the sums of squares of the residuals. It is therefore critical to determine the optimal amount of shrinkage. This can be determined in a ten-fold crossvalidation with shrinkage values $(s)$ between 0.006 and 0.36 in steps of 0.006 . Toward this end, the sample was divided into ten subsamples. A regression analysis was performed on one subset and validated on the other nine subsets. To reduce variability, ten rounds of crossvalidation were performed using different shrinkage values, and the validation results were averaged over the ten rounds. 

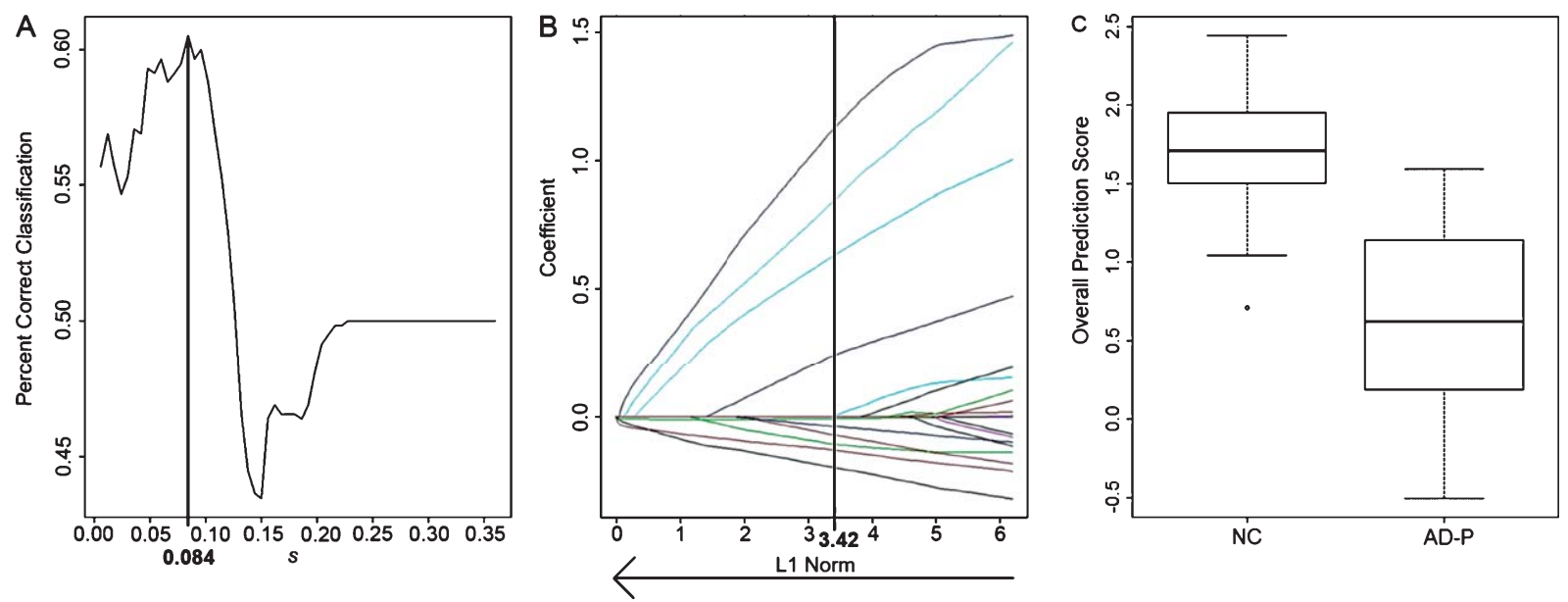

Fig. 1. A) Correct classification rates from ten-fold cross-validation for shrinkage values $s$ of the sum of absolute regression coefficients (L1norm). Parameter $s$ is the ratio of the L1-norm of the penalized model over the L1-norm of the unrestricted model. The optimal $s$ of 0.084 (vertical line) is rounded to 0.08 for convenience and results in a correct classification rate of $60.4 \%$. B) Profile plot of coefficients in the lasso model (each line represents the coefficients of one predictor variable) when shrinking the L1-norm of the regression coefficients from 3.72 (corresponding to $s=0.08$, vertical line) down to 0 . As the L1-norm decreases, more and more coefficients shrink to 0 and therefore drop from the model. Coefficients of the optimal model ( $\mathrm{L} 1=3.42,11$ predictor variables) are shown in Table 3 . C) Boxplots of the overall prediction scores for NC and AD-P participants from the optimal lasso model.

\section{RESULTS}

For completeness, we summarize the performance of the $\mathrm{NC}$ and $\mathrm{AD}-\mathrm{P}$ groups on each of the 115 cognitive, behavioral, and medical variables in Supplementary Table 2. Since the number of comparisons $(\mathrm{k}=115)$ was larger than the group size, we applied the lasso technique [42]. The optimal CCR was defined as the point at which the corresponding $s$ yielded the best prediction for overall group membership. The highest percentage of correct classification was achieved with a shrinkage of $s=0.08$, i.e., at $8 \%$ of the maximal possible sum of all coefficients. The sum of all coefficients was consequently shrunk by more than $90 \%$ and resulted in the correct classification of AD-P and NC in $60.4 \%$ of cases (Fig. 1A).

The selection of variables could therefore be determined by constraining the sum of the absolute coefficients to $8 \%$ of the maximal possible sum of coefficients (L1), where the maximal possible correct classification of $60.4 \%$ was reached. This corresponded to an absolute sum of coefficients of 3.72 (Fig. 1B). Reductions of more than $90 \%$ of the maximal possible sum of all coefficients set most of the 115 coefficients to 0 , thus dismissing them from the model. However, 11 coefficients were different from 0 at this point, indicating that their corresponding variables predicted group membership of the study samples with the optimal possible correct classification rate.
These regression coefficients (Table 3) show the contribution of each variable to the prediction of group membership $(0=\mathrm{NC}, 1=\mathrm{AD}-\mathrm{P})$, i.e., the probability of being in the AD-P group. Depending on the scale (i.e., low/high score implies better/worse performance or vice versa), coefficients show a corresponding positive or negative amplitude. Odd's ratios confirmed the strengths each variable's effect to the prediction of AD$\mathrm{P}$ group membership. The signs of all coefficients are consistent with poorer performance in the AD-P group.

The first variable in the model and thus the variable with the smallest impact on group discrimination was the total score of the Wechsler Adult Intelligence Scale (WAIS) block design, with a coefficient of $b=-0.01$. Thus, AD-P individuals performed worse on this task an average of eight years prior to their diagnosis than those who remain healthy within the same timeframe. The lasso technique further revealed that with increasing L1-norm and simultaneously increasing importance for the model, future AD patients exhibited more repetitions on the phonemic fluency task $(b=0.03)$, a lower total delayed recall score on the CERAD figures task $(b=-0.04)$, a lower response bias $(b=-0.08)$ on the California Verbal Learning Test (CVLT) recognition test, fewer intrusion errors on the CERAD word-list $(b=-0.11)$, a lower score on the WAIS block design items $5(b=-0.14)$ and $4(b=-0.21)$, and more errors in on the phonemic fluency task $(b=0.27)$ than matched control peers who maintained 
Table 3

The eleven variables selected by the lasso analysis best discriminating between normal control participants and individuals who progressed to $\mathrm{AD}$ after an average of 8 years. The order of variables corresponds to the order in which they were selected in the lasso analysis (Fig. 1B, from top to bottom). The magnitudes of the coefficients reflect their ability to predict group membership. Odds Ratios reflect the strength of variable correlations between groups

\begin{tabular}{|c|c|c|c|}
\hline Test/Assessment & Variable & Coeffic & /Odds ratio \\
\hline Memory & $\begin{array}{l}\text { Self-reported } \\
\text { memory } \\
\text { complaints }\end{array}$ & 1.21 & 3.35 \\
\hline $\begin{array}{l}\text { Medical } \\
\text { background }\end{array}$ & $\begin{array}{l}\text { Self-reported } \\
\text { current heart } \\
\text { problems }\end{array}$ & 0.92 & 2.52 \\
\hline Mood changes & $\begin{array}{l}\text { Self-reported } \\
\text { feeling of sadness }\end{array}$ & s 0.68 & 1.98 \\
\hline $\begin{array}{l}\text { Phonemic Fluency } \\
\text { S-words }\end{array}$ & Errors & 0.27 & 1.31 \\
\hline $\begin{array}{l}\text { Phonemic Fluency } \\
\text { S-words }\end{array}$ & Repetitions & 0.03 & 1.03 \\
\hline WAIS Block design & Total points & -0.01 & 0.99 \\
\hline CERAD Figures & Delayed recall & -0.04 & 0.96 \\
\hline CVLT Recognition & Response bias & -0.08 & 0.92 \\
\hline CERAD word list & Intrusion errors & -0.11 & 0.89 \\
\hline WAIS Block design & Item 5 & -0.14 & 0.87 \\
\hline WAIS Block design & Item 4 & -0.21 & 0.81 \\
\hline
\end{tabular}

their performance within the next eight years. Notably, the lasso technique selected many qualitative measures of cognitive functioning (e.g., repetition and intrusion errors). Remarkably, seven of the 29 future AD-patients affirmed feelings of sadness $(b=0.68)$, whereas only a single NC did so. Finally, while no $\mathrm{NC}$ reported current heart problems $(b=0.92)$ or memory complaints $(b=1.21)$, five of the AD-P individuals did. We stress that these differences between AD-P and $\mathrm{NC}$ individuals were detected when AD-P were in a preclinical, symptom-free phase of the disease.

To determine the discriminability of the lasso model, an overall prediction score was computed for each individual to determine each individual's probability of being assigned to the AD-P group based on the lasso model. A comparison of the two groups' prediction scores using the student's $t$-test revealed a significant between-group difference (NC mean: $\mu=0.525$; AD-P mean: $\mu=0.560$; Welch $t=-7.961, p<0.0001$; Fig. 1C). As expected, NC participants obtained a lower mean score than AD-P patients, indicating that $\mathrm{NC}$ individuals' estimated risk to develop $\mathrm{AD}$ was significantly lower than AD-P patients'.

\section{DISCUSSION}

Multiple neuropsychological performance measures significantly predicted progression to $\mathrm{AD}$ an average of eight years prior to diagnosis: subjective and objective measures of verbal learning and memory, delayed recall of figural information, the Block Design subtest, numbers of errors and repetitions on letter fluency, as well as self-reported feelings of sadness and cardiac problems. Remarkably, three of the selected predictors are based on self-reports, and three are qualitative in nature. These findings suggest that subjective, qualitative, and quantitative measures of verbal and figural episodic memory performance, visuospatial functioning, frontal lobe functioning (error control), as well as mild depressive and cardiovascular signs, represent a cluster of symptoms that long antedate the emergence of AD. Notably, these results are inconsistent with recent models of the evolution of cognitive, clinical, and biomarker changes in AD [43, 44], which hypothesize that cognitive impairments are not apparent in the preclinical phase preceding mild cognitive impairment (MCI).

Verbal and visual episodic learning and memory measures were among the best predictors of progression to $\mathrm{AD}$ (Table 3 ). These findings were expected and are consistent with the sites of beginning neurofibrillary pathology in $\mathrm{AD}$ [23], i.e., the medial perirhinal cortex (i.e., transentorhinal cortex [45]), entorhinal cortex and hippocampus, structures essential for normal episodic memory functioning. In contrast to previous reports on the predictive utility of quantitative measures of episodic memory performance, we found that subjective and more subtle, qualitative measures of episodic memory functioning best predicted future $\mathrm{AD}$, i.e., subjective reports of memory difficulties, intrusion errors [3], and a liberal response bias on recognition. This latter memory measure is of particular interest, as a recent study found that nonhuman primates with ablated perirhinal cortices produced an increased number of false positives during a recognition memory task [46]. Thus, an increased propensity to judge non-target items as familiar and belonging to the target set (i.e., false positives) may reflect perirhinal cortex dysfunction resulting from the initial deposition of neurofibrillary pathology in this region. Since the perirhinal cortex also plays a critical role in forming visual object memories, the present finding of decreased visual memory performance in the AD-P group provides converging support for perirhinal cortex dysfunction very early in the course of $\mathrm{AD}$. Indeed, visual memory impairments were associated with metabolic changes in the anterior perirhinal and entorhinal cortices, and predicted progression from MCI to AD with an accuracy of $82 \%$ [47]. Thus, quantitative performance measures of visual memory 
functioning, as well as qualitative performance measures, which elaborate how participants perform a task, may represent potent measures of the future development of AD.

Visuospatial functioning as measured by the Block Design subtest [48] emerged as a significant predictor of future AD in our data. Similarly, Arnáiz and colleagues [49] identified the Block Design as the most effective predictor of progression from $\mathrm{MCI}$ to $\mathrm{AD}$. According to a new framework [50], visuospatial perceptual processing relies on a dorsal pathway from inferior parietal cortex through the posterior cingulate and retrosplenial cortices on to the parahippocampal cortex and the medial temporal lobe (parieto-medial temporal pathway). Concomitant dysfunction of the medial temporal lobe [13] and posterior cingulate cortex [51] characterizes early AD. The present results suggest that medial temporal lobe and/or posterior cingulate cortex dysfunction may surface many years prior to overt $\mathrm{AD}$, potentially disrupting the parietomedial temporal visuospatial processing pathway, with corresponding impairments reflected in measures such as the Block Design subtest.

Two measures from the letter fluency task were selected as discriminators of NC and AD-P participants. We note that the number of errors and repetitions on this task discriminated groups, but not the total number of produced words. Thus, future AD patients demonstrated a failure to inhibit certain responses while searching, accessing and producing words, as opposed to an access or production impairment per se. This pattern indicates a primary dysfunction in orbito-prefrontal rather than medial and dorsolateral prefrontal cortex in the preclinical stage of the disease [52]. The same pattern of normal output with increased number of errors and repetitions has been observed in a comparison of normal control to AD participants [2], although the poor sensitivity of the error measure led Cahn and colleagues [2] to propose that while the presence of errors supported a diagnosis of $\mathrm{AD}$, their absence is of little diagnostic import.

The lasso method selected three additional clinical variables as predictors of future AD. One was a subjective memory complaint, which was reported by $17 \%$ of future $\mathrm{AD}$ patients and none of those who remained healthy. Subjective memory impairment has been found to be a harbinger of further decline in subjects with no cognitive impairment at study entry [31] and has been reported to be an early and strong predictor of AD [32, 53]. Similarly, $17 \%$ of AD-P and none of the NC participants reported current cardiac problems. This parallels the widespread finding from several longitudinal studies that cardiovascular function (as measured by objective measures) significantly predicts progression to AD (e.g., [54]). Lastly, a subjective feeling of sadness (FDD [55]) was endorsed by $24 \%$ of AD-P compared to $3 \%$ of the NC participants. Depressive symptoms that do not even meet criteria for a depressive disorder may be relevant. Indeed, the Religious Orders Study [17] reported that the number of depressive symptoms at baseline predicted progression to $\mathrm{AD}$, and that risk for future $\mathrm{AD}$ increased by about $20 \%$ with each additional symptom of depression (see also [29, 30]). It remains unclear whether early depressive symptomatology represents an actual predictor of progression, a prodromal or early manifestation of the disease [30], or a reaction to self-perceived cognitive decline [29]. Taken together, results of these three variables indicate that despite their low specificity, selfreported changes should be carefully considered in conjunction with other objective measures, in clinical practice as well as in research studies on preclinical markers of $\mathrm{AD}$.

Two important limitations of this study are noted. First, our analysis focused on neuropsychological and clinical measures only. While known to contribute to the detection of $\mathrm{AD}$ in preclinical stages, biomarkers such as amyloid imaging, cerebrospinal fluid markers, or MRI measures were not available, and their interaction with neuropsychological variables may have improved the present CCR of $60.4 \%$. Second, the relatively small number of participants who developed AD and whose neuropsychological baseline results were available for analysis limits the generalizability of our findings. The relatively small sample size compared to the large number of variables necessitated the use of the lasso technique. The applied L1-penalty favors a regression model with a small number of coefficients that offers a good fit to the data, and allows the reliable selection of variables even from among a large starting set [56]. Thus, the lasso technique provides an elegant statistical solution for studies with comprehensive datasets.

A potentially promising methodological approach for studies of preclinical cognitive changes in $\mathrm{AD}$ is the matching of groups according to APOE-status. The lifetime risk of $\mathrm{AD}$ at the age of 85 years without reference to APOE genotype is about five-fold lower than that for ApoE $\varepsilon 4$ carriers [57]. Moreover, APOE $\varepsilon 4$ possession is associated with earlier and faster cognitive decline in patients with $\mathrm{AD}$ [58], and may impact cognitive performance, notably episodic memory functions, in cognitively healthy aged persons [59]. APOE-status is therefore a critical selection 
and matching variable in longitudinal studies of dementia.

The present findings suggest the existence of subjective and subtle quantitative and qualitative signs of preclinical $\mathrm{AD}$ which emerge prior to the ability to characterize amnestic MCI [60] and prior to overt AD. This preclinical cognitive cascade of deficits in verbal and visual memory functioning, visuospatial perception, and executive dysfunctions together with subjective feelings of sadness and memory complaints may antedate overt $\mathrm{AD}$ by several years, and may indeed accompany other suspected biological markers of the preclinical stage of $\mathrm{AD}$ [43]. Our findings are in line with the neuropathological development of Cortical AD neurofibrillary tangles, which start in the perirhinal cortex before moving into the entorhinal cortex and hippocampal formation [23]. Thus, the novel approach implemented here suggests that future $\mathrm{AD}$ patients may best be identified with qualitative functional measures including subjective reports of cognition, mood and health in addition to standard quantitative neuropsychological measures.

\section{ACKNOWLEDGMENTS}

We thank the members of the Basel Study on the Elderly (BASEL) for their participation, and the staff of the Memory Clinic of the Department of Geriatrics for their support. We gratefully acknowledgment the inspiring comments of Prof. Rene Spiegel. This study was supported by grant from the Swiss National Science Foundation (Nr. 3200-049107), the Novartis Foundation, a Swiss National Science Foundation Ambizione Fellowship (to K.I.T.) and the Velux Foundation.

Authors' disclosures available online (http://www.jalz.com/disclosures/view.php?id=1582).

\section{REFERENCES}

[1] Fleisher A, Sowell B, Taylor C, Gamst AC, Petersen RC, Thal LJ (2007) Clinical predictors of progression to Alzheimer disease in amnestic mild cognitive impairment. Neurology 68 , 1588-1595.

[2] Cahn DA, Salmon DP, Bondi MW, Butters N, Johnson SA, Wiederholt WC, Barrett-Connor E (1997) A population-based analysis of qualitative features of the neuropsychological test performance of individuals with dementia of the Alzheimer type: Implications for individuals with questionable dementia. J Int Neuropsychol Soc 3, 387-393.

[3] Fuld PA, Katzman R, Davies P, Terry RD (1982) Intrusions as a sign of Alzheimer dementia: Chemical and pathological verification. Ann Neurol 11, 155-159.
[4] Emery VOB (2011) Alzheimer disease: Are we intervening too late? J Neural Transm 118, 1361-1378.

[5] Collie A, Maruff P (2000) The neuropsychology of preclinical Alzheimer's disease and mild cognitive impairment. Neurosci Biobehav Rev 24, 365-374.

[6] Fabrigoule C, Rouch I, Taberly A, Letenneur L, Commenges D, Mazaux JM, Orgogozo JM, Dartigues JF (1998) Cognitive process in preclinical phase of dementia. Brain 121, 135-141.

[7] Masur DM, Sliwinski M, Lipton RB, Blau AD, Crystal HA (1994) Neuropsychological prediction of dementia and the absence of dementia in healthy elderly persons. Neurology 44, 1427-1432.

[8] Saxton J, Lopez OL, Ratcliff G, Dulberg C, Fried LP, Carlson MC, Newman AB, Kuller L (2004) Preclinical Alzheimer disease: Neuropsychological test performance 1.5 to 8 years prior to onset. Neurology 63, 2341-2347.

[9] Small BJ, Herlitz A, Fratiglioni L, Almkvist O, Bäckman L (1997) Cognitive predictors of incident Alzheimer's disease: A prospective longitudinal study. Neuropsychol 11, 413-420.

[10] Amieva H, Jacqmin-Gadda H, Orgogozo J-M, Le Carret N, Helmer C, Letenneur L, Barberger-Gateau P, Fabrigoule C, Dartigues JF (2005) The 9 year cognitive decline before dementia of the Alzheimer type: A prospective populationbased study. Brain 128, 1093-1101.

[11] Chen P, Ratcliff G, Belle SH, Cauley JA, DeKosky ST, Ganguli M (2000) Cognitive tests that best discriminate between presymptomatic AD and those who remain nondemented. Neurology 55, 1847-1853.

[12] Chen P, Ratcliff G, Belle SH, Cauley JA, DeKosky ST, Ganguli M (2001) Patterns of cognitive decline in presymptomatic Alzheimer disease: A prospective community study. Arch Gen Psychiatry 58, 853-858.

[13] Elias MF, Beiser A, Wolf PA, Au R, White RF, D'Agostino RB (2000) The preclinical phase of alzheimer disease: A 22-year prospective study of the Framingham Cohort. Arch Neurol 57, 808-813.

[14] Jacobs DM, Sano M, Dooneief G, Marder K, Bell KL, Stern Y (1995) Neuropsychological detection and characterization of preclinical Alzheimer's disease. Neurology 45, 957962.

[15] Amieva H, Le Goff M, Millet X, Pérès K, BarbergerGateau P, Jacqmin-Gadda H, Dartigues JF (2008) Prodromal Alzheimer's disease: Successive emergence of the clinical symptoms. Ann Neurol 64, 492-498.

[16] Grober E, Hall CB, Lipton RB, Zonderman AB, Resnick SM, Kawas C (2008) Memory impairment, executive dysfunction, and intellectual decline in preclinical Alzheimer's disease. J Int Neuropsychol Soc 14, 266-278.

[17] Tierney MC, Yao C, Kiss A, McDowell I (2005) Neuropsychological tests accurately predict incident Alzheimer disease after 5 and 10 years. Neurology 64, 1853-1859.

[18] Bäckman L, Jones S, Berger A-K, Jonsson Laukka E, Small BJ (2005) Cognitive impairment in preclinical Alzheimer's disease: A meta-analysis. Neuropsychology 19, 520-531.

[19] Hall CB, Derby C, LeValley A, Katz MJ, Verghese J, Lipton RB (2007) Education delays accelerated decline on a memory test in persons who develop dementia. Neurology 69, 16571664.

[20] Riley KP, Jicha GA, Davis D, Abner EL, Cooper GE, Stiles N, Smith CD, Kryscio RJ, Nelson PT, Van Eldik LJ, Schmitt FA (2011) Prediction of preclinical Alzheimer's disease: Longitudinal rates of change in cognition. J Alzheimers Dis $\mathbf{2 5}$, 707-717. 
[21] Johnson DK, Storandt M, Morris JC, Langford ZD, Galvin JE (2009) Longitudinal study of the transition from healthy aging to Alzheimer disease. Arch Neurol 66, 1254-1259.

[22] Howieson DB, Carlson NE, Moore MM, Wasserman D, Abendroth CD, Payne-Murphy J, Kaye JA (2008) Trajectory of mild cognitive impairment onset. J Int Neuropsychol Soc 14, 192-198.

[23] Braak H, Braak E (1991) Neuropathological stageing of Alzheimer-related changes. Acta Neuropathol 82, 239-259.

[24] De Anna F, Attali E, Freynet L, Foubert L, Laurent A, Dubois B, Dalla Barba G (2008) Intrusions in story recall: When overlearned information interferes with episodic memory recall. Evidence from Alzheimer's disease. Cortex 44, 305-311.

[25] Snodgrass JG, Corwin J (1988) Pragmatics of measuring recognition memory: Applications to dementia and amnesia. J Exp Psychol Gen 117, 34-50.

[26] Dartigues JF, Fabrigoule C, Letenneur L, Amieva H, Thiessard F, Orgogozo JM (1997) Epidemiology of memory disorders. Therapie 52, 503-506.

[27] Berger AK, Fratiglioni L, Forsell Y, Winblad B, Bäckman L (1999) The occurrence of depressive symptoms in the preclinical phase of AD: A population-based study. Neurology 53, 1998-2002.

[28] Wilson RS, Barnes LL, Mendes de Leon CF, Aggarwal NT, Schneider JS, Bach J, Pilat J, Beckett LA, Arnold SE, Evans DA, Bennett DA (2002) Depressive symptoms, cognitive decline, and risk of AD in older persons. Neurology 59, 364370.

[29] Fuhrer R, Dufouil C, Dartigues JF (2003) Exploring sex differences in the relationship between depressive symptoms and dementia incidence: Prospective results from the PAQUID Study. J Am Geriatr Soc 51, 1055-1063.

[30] Chen P, Ganguli M, Mulsant BH, DeKosky ST (1999) The temporal relationship between depressive symptoms and dementia: A community-based prospective study. Arch Gen Psych 56, 261-266.

[31] Reisberg B, Shulman MB, Torossian C, Leng L, Zhu W (2010) Outcome over seven years of healthy adults with and without subjective cognitive impairment. Alzheimers Dement 6, 1124.

[32] Geerlings MI, Jonker C, Bouter LM, Adèr HJ, Schmand B (1999) Association between memory complaints and incident Alzheimer's disease in elderly people with normal baseline cognition. Am J Psych 156, 531-537.

[33] Stern Y, Gurland B, Tatemichi TK, Tang MX, Wilder D, Mayeux R (1994) Influence of education and occupation on the incidence of Alzheimer's disease. JAMA 271, 1004-1010.

[34] Kamat SM, Kamat AS, Grossberg GT (2010) Dementia risk prediction: Are we there yet? Clin Geriatr Med 26, 113-123.

[35] Monsch AU, Thalmann B, Schneitter M, Bernasconi F, Aebi C, Camachova-Davet Z, Stähelin HB (2000) The Basel Study on the Elderly's search for preclinical cognitive markers of Alzheimer's disease. Neurobiol Aging 21, 31.

[36] Morris JC, Heyman A, Mohs RC, Hughes JP, van Belle G, Fillenbaum G, Mellits ED, Clark C (1989) The Consortium to Establish a Registry for Alzheimer's Disease (CERAD). Part I. Clinical and neuropsychological assessment of Alzheimer's disease. Neurology 39, 1159-1165.

[37] Miserez AR, Scharnagl H, Muller PY, Mirsaidi R, Stähelin HB, Monsch A, März W, Hoffmann MM (2003) Apolipoprotein E3Basel: New insights into a highly conserved protein region. Eur J Clin Invest 33, 677-685.

[38] American Psychiatric Association (1994) DSM-IV: Diagnostic and Statistical Manual of Mental Disorders. 4th ed., American Psychiatric Press, Washington, DC.
[39] McKhann G, Drachman D, Folstein M, Katzman R, Price D, Stadlan EM (1984) Clinical diagnosis of Alzheimer's disease: Report of the NINCDS-ADRDA work group under the auspices of Department of Health and Human Services Task Force on Alzheimer's disease. Neurology 34, 939-944.

[40] Mayeux R, Stern Y (2012) Epidemiology of Alzheimer disease. Cold Spring Harb Perspect Med 2, pii: a006239.

[41] Holtzer R, Goldin Y, Zimmerman M, Katz M, Buschke H, Lipton RB (2008) Robust norms for selected neuropsychological tests in older adults. Arch Clin Neuropsychol 23, 531-541.

[42] Tibshirani R (1996) Regression shrinkage and selection via the lasso. J Roy Stat Soc 58, 267-288.

[43] Sperling RA, Aisen PS, Beckett LA, Bennett DA, Craft S, Fagan AM, Iwatsubo T, Jack CR Jr, Kaye J, Montine TJ, Park DC, Reiman EM, Rowe CC, Siemers E, Stern Y, Yaffe K, Carrillo MC, Thies B, Morrison-Bogorad M, Wagster MV, Phelps CH (2011) Toward defining the preclinical stages of Alzheimer's disease: Recommendations from the National Institute on Aging-Alzheimer's Association workgroups on diagnostic guidelines for Alzheimer's disease. Alzheimers Dement 7, 280-292.

[44] Jack CR Jr, Knopman DS, Jagust WJ, Shaw LM, Aisen PS, Weiner MW, Petersen RC, Trojanowski JQ (2010) Hypothetical model of dynamic biomarkers of the Alzheimer's pathological cascade. Lancet Neurol 9, 119-128.

[45] Taylor KI, Probst A (2008) Anatomic localization of the transentorhinal region of the perirhinal cortex. Neurobiol Aging 29, 1591-1596.

[46] McTighe SM, Cowell RA, Winters BD, Bussey TJ, Saksida LM (2010) Paradoxical false memory for objects after brain damage. Science 330, 1408-1410.

[47] Didic M, Ranjeva J-P, Barbeau E, Confort-Gouny S, Fur YL, Felician O, Mancini J, Poncet M, Ceccaldi M, Cozzone $P$ (2010) Impaired visual recognition memory in amnestic mild cognitive impairment is associated with mesiotemporal metabolic changes on magnetic resonance spectroscopic imaging. J Alzheimers Dis 22, 1269-1279.

[48] Wechsler D (1956) Die Messung der Intelligenz Erwachsener, Verlag Hans Huber, Bern.

[49] Arnáiz E, Jelic V, Almkvist O, Wahlund LO, Winblad B, Valind S, Nordberg A (2001) Impaired cerebral glucose metabolism and cognitive functioning predict deterioration in mild cognitive impairment. Neuroreport 12, 851-855.

[50] Kravitz DJ, Saleem KS, Baker CI, Mishkin M (2011) A new neural framework for visuospatial processing. Nat Rev Neurosci 12, 217-230.

[51] Minoshima S, Giordani B, Berent S, Frey KA, Foster NL, Kuhl DE (1997) Metabolic reduction in the posterior cingulate cortex in very early Alzheimer's disease. Ann Neurol 42, 8594.

[52] Crowe SF (1992) Dissociation of two frontal lobe syndromes by a test of verbal fluency. J Clin Exp Neuropsychol 14, 327339.

[53] Dartigues JF, Commenges D, Letenneur D, Barberger-Gateau P, Gilleron V, Fabrigoule C, Mazaux JM, Orgogozo JM, Salamon R (1997) Cognitive predictors of dementia in elderly community residents. Neuroepidemiol 16, 29-39.

[54] Luchsinger JA, Reitz C, Honig LS, Tang MX, Shea S, Mayeux R (2005) Aggregation of vascular risk factors and risk of incident Alzheimer disease. Neurology 65, 545-551.

[55] Kühner C (1997) Fragebogen zur Depressionsdiagnostik nach DSM-IV (FDD-DSM-IV), Hogrefe, Göttingen.

[56] Kohannim O, Hibar DP, Stein JL, Jahanshad N, Hua1 X, Rajagopalan P, Toga AW, Jack CR, Weiner MW, de Zubicaray GI, McMahon KL, Hansell NK, Martin NG, Wright MG, 
Thompson PM (2012) Discovery and replication of gene influences on brain structure using LASSO regression. Front Neurosc 6, 1-13.

[57] Genin E, Hannequin D, Wallon D, Sleegers K, Hiltunen M, Combarros O, Bullido MJ, Engelborghs S, De Deyn P, Berr C, Pasquier F, Dubois B, Tognoni G, Fiévet N, Brouwers N, Bettens K, Arosio B, Coto E, Del Zompo M, Mateo I, Epelbaum J, Frank-Garcia A, Helisalmi S, Porcellini E, Pilotto A, Forti P, Ferri R, Scarpini E, Siciliano G, Solfrizzi V, Sorbi S, Spalletta G, Valdivieso F, Vepsäläinen S, Alvarez V, Bosco P, Mancuso M, Panza F, Nacmias B, Bossù P, Hanon O, Piccardi P, Annoni G, Seripa D, Galimberti D, Licastro F, Soininen H, Dartigues JF, Kamboh MI, Van Broeckhoven C, Lambert JC, Amouyel P, Campion D (2011) APOE and Alzheimer disease: A major gene with semi-dominant inheritance. Mol Psychiatry 16, 903-907.

[58] Zehnder AE, Bläsi S, Berres M, Monsch AU, Stähelin HB, Spiegel R (2008) Impact of APOE status on cognitive maintenance in healthy elderly persons. Int J Geriatr Psychiatry 24, 132-141.

[59] Martins CAR, Oulhaj A, de Jager CA, Williams JH (2005) APOE alleles predict the rate of cognitive decline in Alzheimer disease: A nonlinear model. Neurology 65, 18881893.

[60] Albert MS, DeKosky ST, Dickson D, Dubois B, Feldman HH, Fox NC, Gamst A, Holtzman DM, Jagust WJ, Petersen RC, Snyder PJ, Carrillo MC, Thies B, Phelps CH (2011) The diagnosis of mild cognitive impairment due to Alzheimer's disease: Recommendations from the National Institute on Aging-Alzheimer's Association workgroups on diagnostic guidelines for Alzheimer's disease. Alzheimers Dement 7, 270-279.

[61] Folstein MF, Folstein SE, McHugh PR (1975) Mini Mental State - a practical method for grading the cognitive state of patients for the clinician. J Psych Res 12, 189-198.

[62] Reitan R (1958) Validity of the Trail Making Test as an indicator of organic brain damage. Perc Mot Skills 8, 271-276.

[63] Zimmermann P, Fimm B (1993) Testbatterie zur Erfassung von Aufmerksamkeitsstoerungen, Psytest, Freiburg.

[64] Delis DC, Kramer JH, Kaplan E, Ober BA (1987) California Verbal Learning Test, Psychological Corporation, San Antonio.

[65] Kaplan E, Goodglass H, Weintraub S (1978) The Boston Naming Test, Veterans Administration Medical Center, Boston.

[66] Nelson HE (1982) National Adult Reading Test (NART): Test Manual, NFER-Nelson, Windsor.

[67] Lehrl S (1999) Mehrfachwahl-Wortschatz-Intelligenztest, Hogrefe, Göttingen.

[68] Isaacs B, Kennie AT (1973) The Set test as an aid to the detection of dementia in old people. Br J Psych 123, 467-470.

[69] Thalmann B, Spiegel R, Stähelin HB, Brubacher D, ErminiFünfschilling D, Bläsi S, Monsch AU (2002) Dementia screening in general practice: Optimized scoring for the Clock Drawing Test. Brain Aging 2, 36-43. 